\title{
Quality Indicators Compliance Survey in Indian Intensive Care Units
}

\author{
Munta Kartik, Palepu B. N. Gopal' ${ }^{1}$ Rahul Amte \\ Department of Critical Care Medicine, Yashoda Hospital, Somajiguda, ${ }^{1}$ Department of Critical Care Medicine, Continental Hospital, Hyderabad, Telangana, India
}

\section{Abstract}

Context: The quality of health care and outcomes of Intensive Care Unit (ICU) have been a major subject of discussion in the past decade. Quality indicators in ICUs maintain an order of uniformity and standard care of delivery across ICUs. Aims: In this study, we tried to analyze the percentage compliance of quality indicators in ICU across our country. Methods: Four hundred complete questionnaire forms were collected in two stages by means of conducting a survey and through email responses to the survey questionnaire. Data were tabulated and evaluated in percentage responses. Results: Monitoring of infection control measures such as hand hygiene (77\%), monitoring of ICU-acquired infections (>75\%), and quality and policy measures ( $>70 \%)$ were promising. Improvements are required in following end-of-life pathways (52\%) and staffing patterns in ICU. ICU discharge timings (41\%), standardized mortality ratio monitoring (39\%), and multidisciplinary rounds (58\%) in ICUs are few areas we need to develop further. Conclusion: The future of critical care looks promising with growing number of trained intensivists and hospitals functioning with an average ICU bed strength of 30-40. Such surveys need to be performed regularly to improve the patient care and safety across ICUs.

Keywords: Critical care, infection control, patient care, quality indicators, survey

\section{INTRODUCTION}

Quality management is crucial in Intensive Care Units (ICUs), and quality indicators are used as tools to monitor performance improvement. ICU outcomes vary widely among hospitals and are likely to be related to differences in ICU design and care pathways. Understanding of these factors may reduce variation and will lead to improving patient care. The objectives of our survey were to study whether optimum quality standards are implemented in Indian ICUs according to local resource availability and to locate areas of noncompliance.

\section{Methods}

The survey was conducted through a questionnaire, which was designed to gather information from responders. The survey forms were distributed at one of the Annual National Congresses of the Indian Society of Critical Care Medicine and were also e-mailed to randomly selected members of the same organization. The questionnaire elicited responses regarding their ICU's professional status, details of their hospitals and ICUs setup, compliance of quality indicators

\begin{tabular}{|l|l|}
\hline \multicolumn{3}{|c|}{ Access this article online } \\
\hline Quick Response Code: & Website: \\
& www.ijccm.org \\
\hline
\end{tabular}

such as infection control measures, patient safety, and outcome parameters. The 400 completely filled forms were analyzed, and percentages were calculated for each response. The questionnaire was categorized into three sections, which included questions regarding demographics details, human resource-related parameters, and quality indicator compliance. These parameters have been selected from recommendations by studies pertaining to quality assessment of ICUs.

\section{RESULTS}

\section{Demographic results}

Maximum responders in the survey were male intensivists (70\%) in the age group of 30-40 years [Figure 1]. A majority of responders belong to the subspecialties of anesthesia $(28 \%)$ followed by intensivists (27\%) [Figure 2]. Maximum

Address for correspondence: Dr. Kartik Munta, Yashoda Hospital, Somajiguda, Hyderabad - 500 082, Telangana, India. E-mail: kartikmunta@yahoo.com

This is an open access article distributed under the terms of the Creative Commons Attribution-NonCommercial-ShareAlike 3.0 License, which allows others to remix, tweak, and build upon the work non-commercially, as long as the author is credited and the new creations are licensed under the identical terms.

For reprints contact: reprints@medknow.com

How to cite this article: Kartik M, Gopal PB, Amte R. Quality indicators compliance survey in Indian intensive care units. Indian J Crit Care Med 2017;21:187-91. 
responses came from consultants (51\%) followed by registrars (30\%) [Figure 3]. Most of them were intensivists working in corporate hospitals (60\%) [Figure 4] having an average bed strength of around 300 and above $(62 \%)$ with most of the ICUs having bed strength ranging from 10 to 30 beds (68\%) [Figure 5]. Most of the responders were working in mixed ICUs (45\%) with open type of ICU setup (72\%) and only 14\% of them being closed ICUs [Figures 6 and 7].

\section{Human resource-related parameters}

This category dealt with questions relating to the staffing patterns of the ICUs. We started off knowing about the number of hours a trained intensivist was present in their ICU. The response was maximum for $24 \mathrm{~h}(37 \%)$ closely followed by $8 \mathrm{~h}$ presence in $32 \%$ of responders [Figure 8]. In response to the question of compliance to ICU admission criteria, 39\% (156 out of 400 ) reported $50 \%-75 \%$ compliance followed by $30 \%$ (120 out of 400 ) reporting a compliance of $25 \%-50 \%$

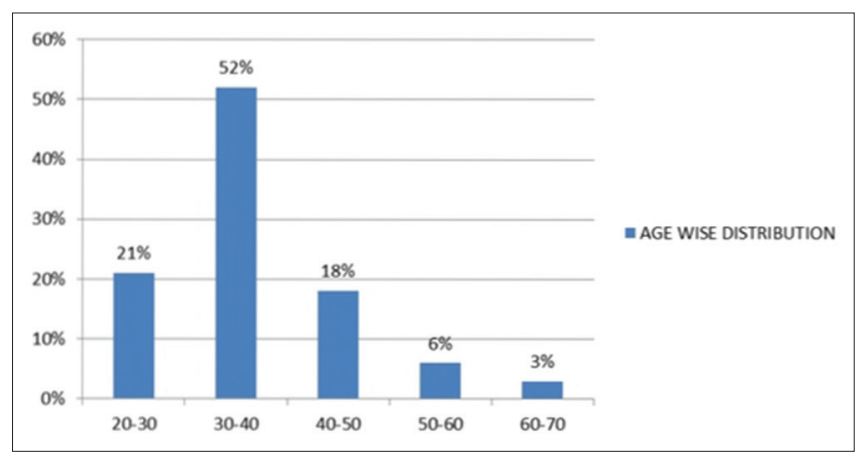

Figure 1: Age distribution of the responders

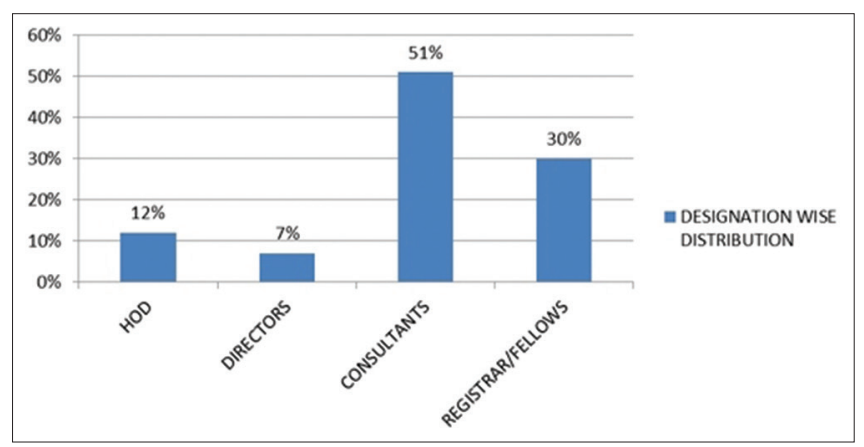

Figure 3: Designation wise distribution

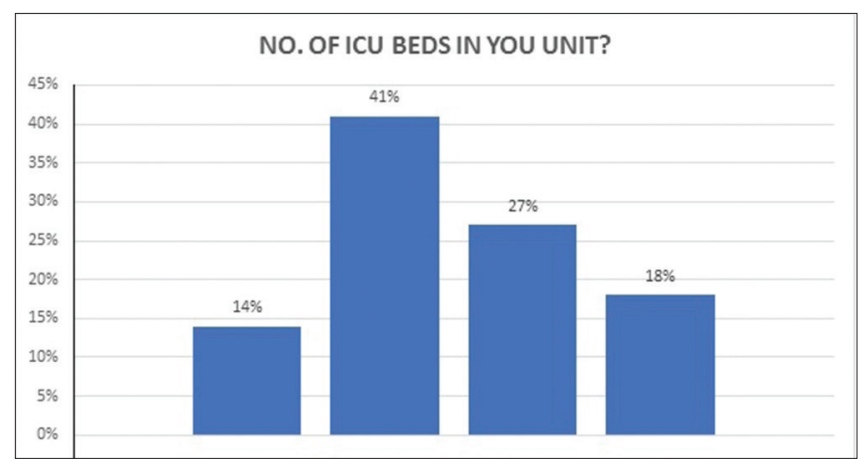

Figure 5: Bed strength in Intensive Care Units
[Figure 9]. ICU beds were being fully occupied for more than $50 \%$ of the time in a year according to the majority of responders (43\%) [Figure 10]. Readmission rates in ICUs were being reported to be $<25 \%$ according to the $82 \%$ of responders. Nursing staff allocation is a major problem in many hospitals in our country. Maximum responders (47\%) had nurse-to-patient ratio for ventilated patient of $1: 2$ and (39\%) responders were strictly abiding by 1:1 nursing care [Figure 11], whereas in nonventilated patients, the response was maximum for $1: 3(46 \%)$ ratio followed by $1: 2(42 \%)$ ratio [Figure 12].

\section{Infection control issues}

This category comprised questions regarding the measures taken by the ICUs and hospital authorities to prevent the spread of nosocomial infection. Hand hygiene [Figure 13] plays a pivotal role in infection control, and when asked about the same $77 \%$ (308 out of 400 ) responders reported compliance

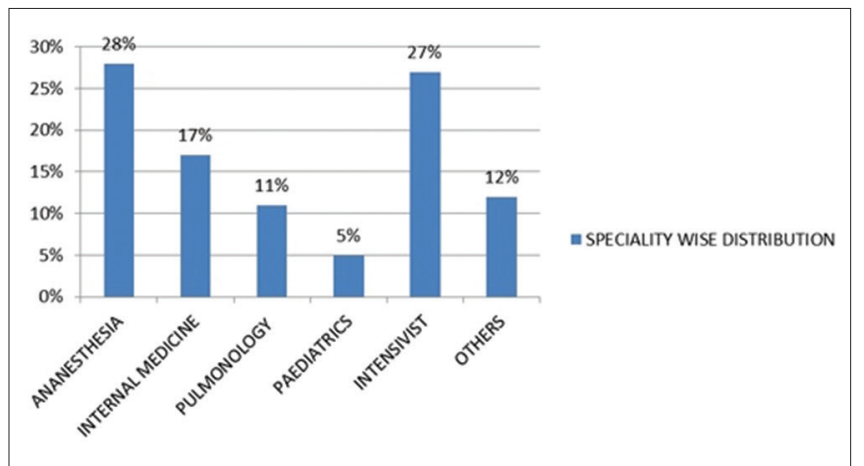

Figure 2: Specialty wise distribution

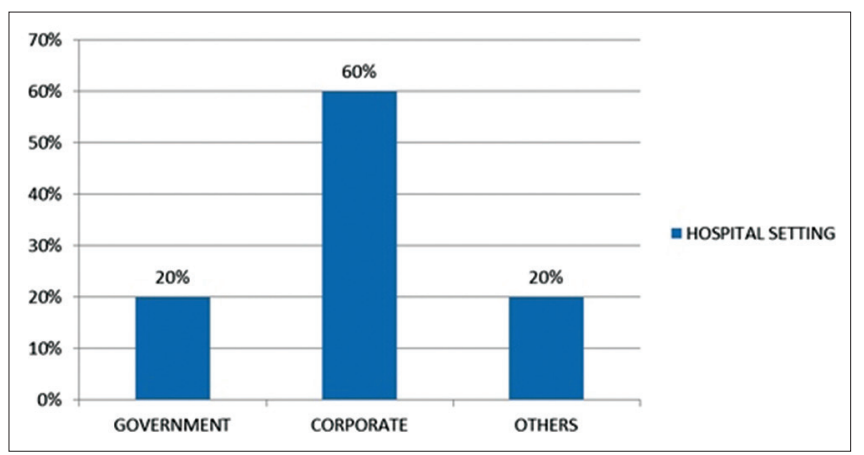

Figure 4: Type of hospital setting

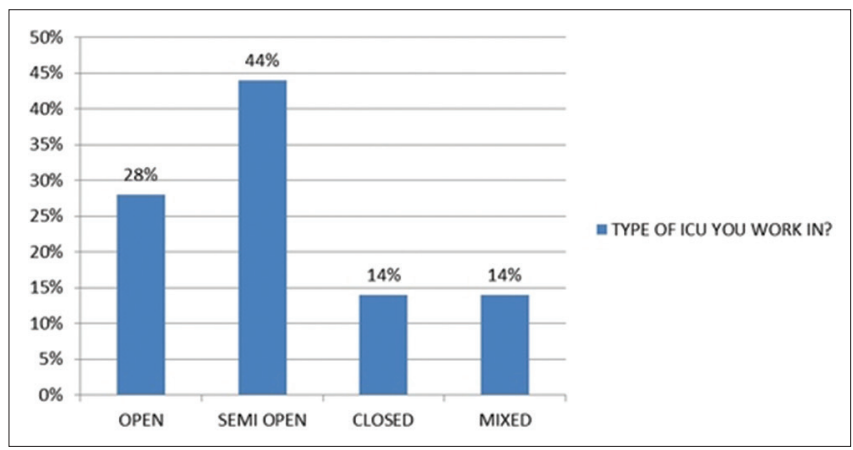

Figure 6: Type of Intensive Care Unit 


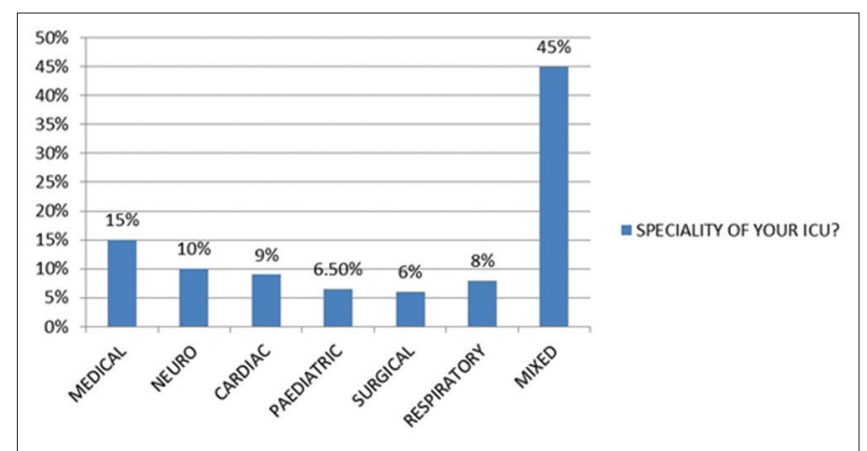

Figure 7: Intensive Care Unit specialty wise distribution

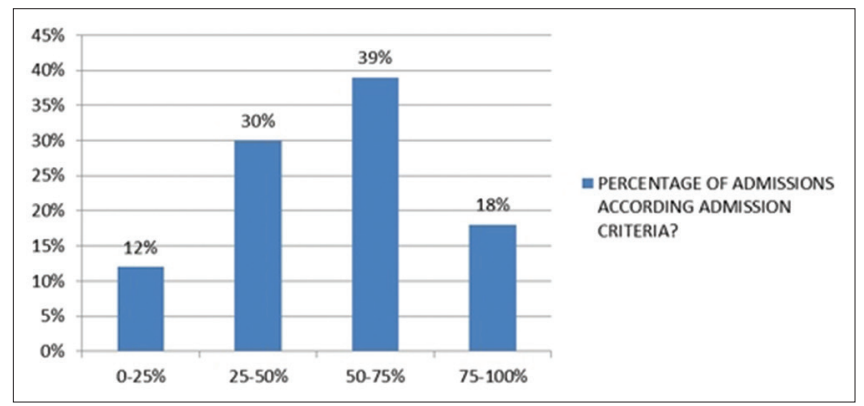

Figure 9: Compliance of admission criteria

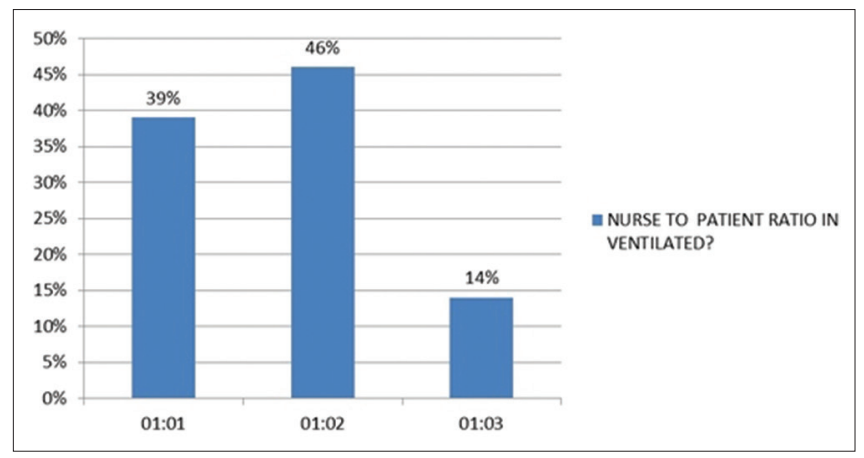

Figure 11: Nurse-to-patient ratio for ventilated patients

to hand washing with either alcohol, chlorhexidine, or soap water. Out of them, $80 \%$ (246 out of 308) were washing their hands before and after examining the patient, whereas $74 \%$ (228 out of 308 ) were compliant to hand washing before and after entering ICU. The surveillance percentages of ventilator-associated pneumonia (VAP), catheter-related bloodstream infection (CRBSI), catheter-associated urinary tract infection (CAUTI), and methicillin-resistant Staphylococcus aureus infections in the ICUs were found to be encouraging with more than $75 \%$ of units being compliant for each of them [Figure 14].

\section{Quality and policy issues}

Every ICU has protocols framed to be followed for better outcomes. In this category, we focused to assess the compliance percentages of widely accepted quality improvement programs in ICUs. Regular review of unit morbidity and mortality was being followed in the ICUs of $68 \%$ of responders. ICU norms

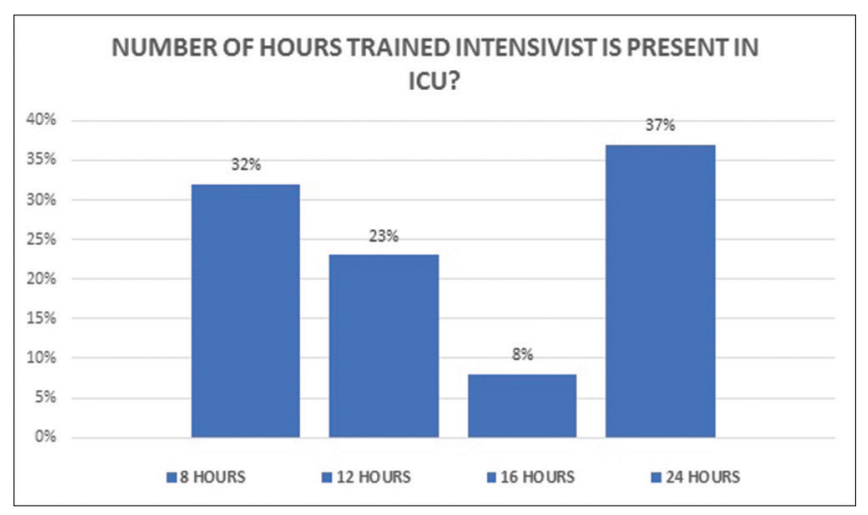

Figure 8: Hours of trained intensivist presence

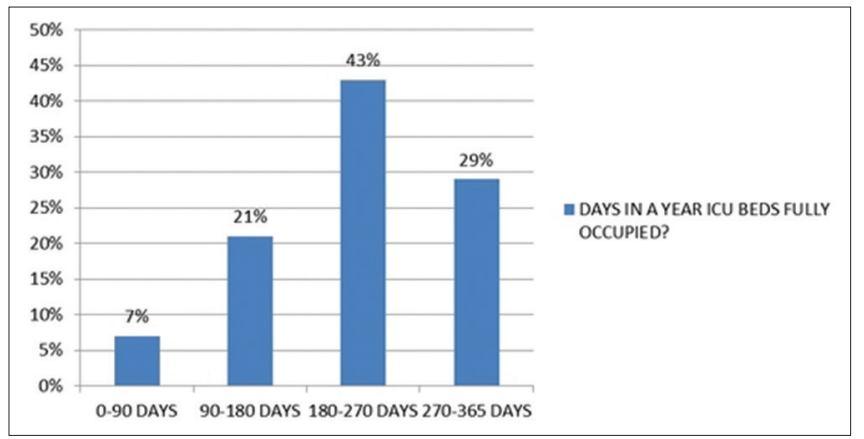

Figure 10: Intensive Care Unit bed occupancy in a year

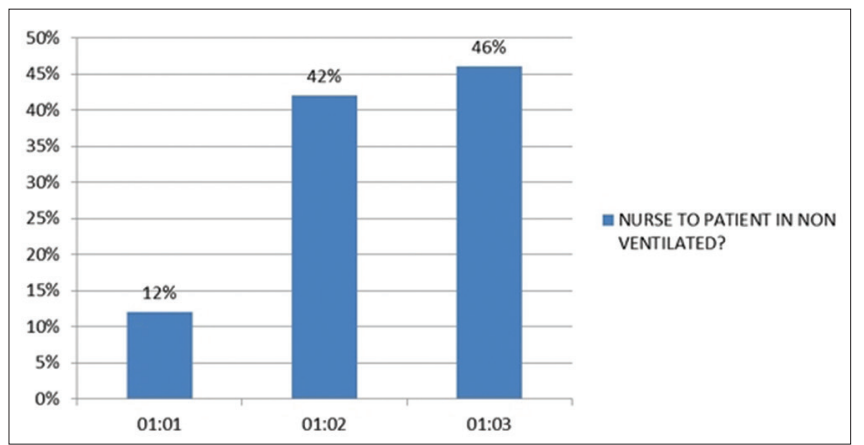

Figure 12: Nurse-to-patient ratio for nonventilated patients

such as structured handover were being followed by $79 \%$, early initiation of enteral nutrition by $95 \%$, maintenance of daily goal sheet by $73 \%$, and isolation of infected patients by $64 \%$ of responders.

Needle stick injury reporting was followed by $84 \%$ intensivists, suggesting knowledge and awareness among health-care workers regarding needle stick injuries. Decubitus ulcer monitoring (91\%) and patient injury or fall monitoring $(85 \%)$ were reported in our survey. End-of-life (EOL) care pathway was in place in only $52 \%$ of responder's ICUs and only $39 \%$ monitored standardized mortality ratio (SMR). ICU discharges were happening after $8 \mathrm{pm}$ in $41 \%$ of responder's ICUs, and concept of multidisciplinary rounds was being followed by $58 \%$ [Figure 15]. 


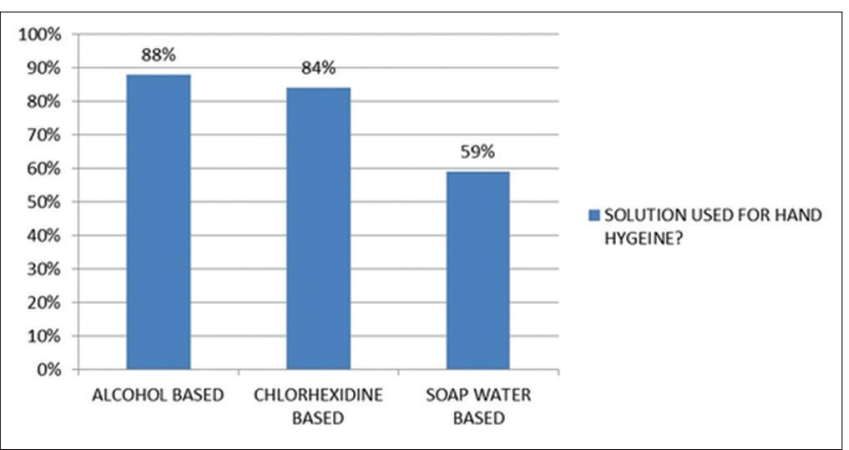

Figure 13: Solutions used for hand hygiene

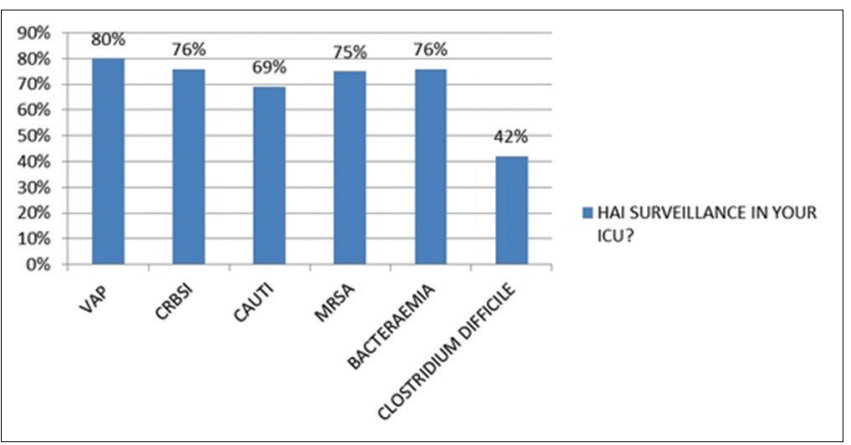

Figure 14: Hospital-acquired infections' surveillance

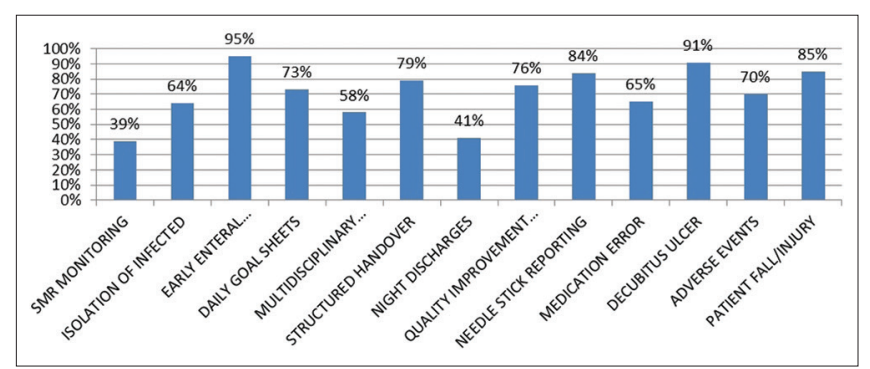

Figure 15: Quality and policy issues compliance

\section{Discussion}

Indian critical care scenario has seen emergence of aspiring intensivists training and practicing critical care in tertiary hospitals in the recent times which reflects in the survey with maximum responses coming in the form of young consultants and registrars. ICUs in India are mostly semi-open and mixed in nature. They are mostly 10-30 bedded. Trained staff in the form of intensivists and nurses are less than required for a large number of critical care beds required across the country. Twenty-four hours intensivist coverage has been shown to improve outcome in patients admitted in ICUs. ${ }^{[1]}$ Twenty-four hours presence of trained intensivists has been only $37 \%$ in our survey, which can be attributed to scarcity of qualified intensivists and resource limitations in the country. High nurse-to-patient ratio has been shown to improve outcomes of ICUs. ${ }^{[2,3]}$ However, cost constraints and staff scarcity seem to have affected the nursing care to ICU patients in the study. Maximum response was seen to nurse patient ratio of
$1: 2(47 \%)$ for ventilated and 1:3 (46\%) for non ventilated patients. Isolation of infected patients has been recognized as a preventive strategy in containing spread of diseases in ICU. ${ }^{4]}$ In our survey, isolation of communicable transmitted disease cases was being followed by $64 \%$ of responders. Admission criteria to ICUs help in the judicious utilization of scarce and cost intense facilities. ${ }^{[5]}$ It has been observed that compliance was only $39 \%$ and it needs to be improved to render better care to patients in already overburdened and understaffed ICUs.

Infection control plays a prominent role in determining outcomes of any ICU. Its' importance has grown by leaps and bounds in our country. With the emergence of antibiotic-resistant organisms, the importance of hand hygiene in hospitals has emerged as a priority for the hospital administrators. Hand hygiene is one of the most important strategies to prevent healthcare-associated infection. ${ }^{[6,7]}$ Maximum ICUs are practicing the norms of hand hygiene with either alcohol, chlorhexidine, or soap water before and after examining patient as well as during before and after entering ICUs. According to a study done at Post Graduate Institute of Medical Education and Research, it was found that the average compliance with hand washing was around $86.0 \%$ which differed significantly among professional health-care workers with higher compliance among nurses $(94.0 \%)$, followed by physicians $(86.2 \%)$ and least by other health-care $\operatorname{staff}(76.2 \%){ }^{[8]}$

Hospitals have been monitoring unit acquired bacteremia in more than $75 \%$ of ICUs in the form of VAP, CAUTI, and CRBSI rates. Hospital-associated infection has been a cause of increased stay and beds nonavailability for ICU requiring patients. ${ }^{[9,10]}$ According to Scottish ICU national survey, 96\% of their ICUs met these criteria which led to better preventive strategies to avoid infections in ICU, thereby decreasing morbidity and mortality. ${ }^{[11]}$

Protocols are being followed in most of the ICUs across the country. Knowledge propagation by means of internet and practice of evidence-based medicine has led to the widespread of implementation of protocols in ICUs. It has been found in the survey that compliance has been more than $75 \%$ for quality and policy measures. They include parameters such as structured handover $(79 \%)$ which has been considered a vital tool for successful intensive care management ensuring effective communication and coordination between physicians. ${ }^{[12,13]}$ Early initiation of enteral feeds (95\%) which is known to decrease morbidity and reduce infectious complications. ${ }^{[14-16]}$ Implementing daily maintenance of goal sheets (73\%) leads to improved communication among team members and reduction in ICU length of stay. ${ }^{[17]}$ Health-care workers are at risk of occupational acquisition of HIV and other viral infections such as hepatitis due to accidental exposure to infected blood and body fluids. ${ }^{[18]}$ Decubitus ulcers occurring in bedridden patients are known to cause increased physical and economic burden to ICUs. ${ }^{[19]}$ Needle stick injury reporting (84\%) has been encouraging as is also decubitus ulcer reporting (91\%) 
and patient injury/fall reporting (85\%). Reporting of such injuries is a critical step in initiating early preventive measures. EOL care is collective effort toward providing comfort care for people with terminal, incurable, and life-crippling illness to provide a peaceful life before they die. ${ }^{[20]}$ EOL pathway in ICU was followed by only $52 \%$ of ICUs, which can be seen as a shortfall due to cultural and religious factors prevailing in this part of the world. Night discharges due to increasing pressure on ICU beds have been shown to have increase mortality. ${ }^{[21,22]}$ Nearly $41 \%$ responders still reported night time discharges pointing toward the scarcity and demand for ICU monitoring in the night time, the reasons for which could be debated. SMR is an invaluable parameter to compare outcomes between ICUs providing an opportunity for ICUs in improving their processes and techniques. ${ }^{[23]}$ Daily rounds conducted with a multidisciplinary team approach have yielded mortality benefits among medical ICU patients. ${ }^{[24]}$ Both SMR monitoring (39\%) and multidisciplinary team rounds $(58 \%)$ need to be improved as their compliance percentages are not up to the mark when compared to rest of the world.

\section{Conclusion}

Implementation of infection control practices seems to be on par with international standards in our country. Underperformance of staff deployment and patient movement indices can be attributed to the economic and cultural patterns prevalent in our setup. Enforcement of multidisciplinary rounds seems to be inadequate and has to be improved to enhance patient care. We need routine mortality and morbidity reviews and SMR policies to give further insight into ICU performance. While there is an urgent need to develop and implement EOL pathways conducive to our culture, this issue is being addressed by our professional organizations. Standard setting organizations such as National Accreditation Board for Hospitals and Healthcare Providers and Joint Commission International have made an impact in developing structured quality protocol implementation in Indian hospitals and their ICUs. Our study points to the need for regular surveying and ensuring course correction in the field of critical care medicine which is growing by leaps and bounds in our country.

\section{Financial support and sponsorship}

Nil.

\section{Conflicts of interest}

There are no conflicts of interest.

\section{References}

1. Pronovost PJ, Angus DC, Dorman T, Robinson KA, Dremsizov TT, Young TL. Physician staffing patterns and clinical outcomes in critically ill patients: A systematic review. JAMA 2002;288:2151-62.

2. Amaravadi RK, Dimick JB, Pronovost PJ, Lipsett PA. ICU nurse-to-patient ratio is associated with complications and resource use after esophagectomy. Intensive Care Med 2000;26:1857-62.

3. Tarnow-Mordi WO, Hau C, Warden A, Shearer AJ. Hospital mortality in relation to staff workload: A 4-year study in an adult Intensive-Care Unit. Lancet 2000;356:185-9.

4. Guideline for Isolation Precautions: Preventing Transmission of Infectious Agents in Healthcare Settings. Available from: http://www. cdc.gov/hicpac/pdf/isolation/Isolation2007.pdf. [Last accessed on 2014 Mar 10].

5. Bakker J, Damen J, van Zanten AR, Hubben JH. Protocollencommissie nederlandse vereiniging voor intensive care. Admission and discharge criteria for intensive care departments. Ned Tijdschr Geneeskd 2003; 147:110-5.

6. Pittet D, Allegranzi B, Storr J. The WHO clean care is safer care programme: Field-testing to enhance sustainability and spread of hand hygiene improvements. J Infect Public Health 2008;1:4-10.

7. Pittet D, Hugonnet S, Harbarth S, Mourouga P, Sauvan V, Touveneau S, et al. Effectiveness of a hospital-wide programme to improve compliance with hand hygiene. Infection Control Programme Lancet 2000;356:1307-12.

8. Sharma R, Sharma M, Koushal V. Hand washing compliance among healthcare staff in Intensive Care Unit (ICU) of a multispecialty hospital of North India. J Hosp Adm 2012;1:27-33.

9. Dendle C, Martin RD, Cameron DR, Grabsch EA, Mayall BC, Grayson ML, et al. Staphylococcus aureus bacteraemia as a quality indicator for hospital infection control. Med J Aust 2009;191:389-92.

10. Pronovost P, Needham D, Berenholtz S, Sinopoli D, Chu H, Cosgrove S, et al. An intervention to decrease catheter-related bloodstream infections in the ICU. N Engl J Med 2006;355:2725-32.

11. The Scottish Intensive Care Society Audit Group. Audit of Critical Care in Scotland 2014, Reporting on 2013. Available from: http:// www.sicsag.scot.nhs.uk/docs/SICSAG-report-2014-web.pdf?1. [Last accessed on 2015 Apr 06].

12. Wayne JD, Tyagi R, Reinhardt G, Rooney D, Makoul G, Chopra S, et al. Simple standardized patient handoff system that increases accuracy and completeness. J Surg Educ 2008;65:476-85.

13. Haig KM, Sutton S, Whittington J. SBAR: A shared mental model for improving communication between clinicians. Jt Comm J Qual Patient Saf 2006;32:167-75.

14. Roberts SR, Kennerly DA, Keane D, George C. Nutrition support in the Intensive Care Unit. Adequacy, timeliness, and outcomes. Crit Care Nurse 2003;23:49-57.

15. Doig GS, Heighes PT, Simpson F, Sweetman EA, Davies AR. Early enteral nutrition, provided within $24 \mathrm{~h}$ of injury or Intensive Care Unit admission, significantly reduces mortality in critically ill patients: A meta-analysis of randomised controlled trials. Intensive Care Med 2009;35:2018-27.

16. Marik PE, Zaloga GP. Early enteral nutrition in acutely ill patients: A systematic review. Crit Care Med 2001;29:2264-70.

17. Pronovost P, Berenholtz S, Dorman T, Lipsett PA, Simmonds T, Haraden C. Improving communication in the ICU using daily goals. J Crit Care 2003;18:71-5.

18. Trim JC, Elliott TS. A review of sharps injuries and preventative strategies. J Hosp Infect 2003;53:237-42.

19. Health Quality Ontario. Pressure ulcer prevention: An evidence-based analysis. Ont Health Technol Assess Ser 2009;9:1-104.

20. Myatra SN, Salins N, Iyer S, Macaden SC, Divatia JV, Muckaden M, et al. End-of-life care policy: An integrated care plan for the dying: A Joint Position Statement of the Indian Society of Critical Care Medicine (ISCCM) and the Indian Association of Palliative Care (IAPC). Indian J Crit Care Med 2014;18:615-35.

21. Goldfrad C, Rowan K. Consequences of discharges from intensive care at night. Lancet 2000;355:1138-42.

22. Tobin AE, Santamaria JD. After-hours discharges from intensive care are associated with increased mortality. Med J Aust 2006;184:334-7.

23. Afessa B, Gajic O, Keegan MT. Severity of illness and organ failure assessment in adult Intensive Care Units. Crit Care Clin 2007;23:639-58.

24. Kim MM, Barnato AE, Angus DC, Fleisher LA, Kahn JM. The effect of multidisciplinary care teams on Intensive Care Unit mortality. Arch Intern Med 2010;170:369-76. 